University of Massachusetts Amherst

ScholarWorks@UMass Amherst

Travel and Tourism Research Association: Advancing Tourism Research Globally

\title{
Domestic Tourism Demand of Urban and Rural Residents in China: Does Relative Income Matter?
}

Yang Yang

Department of Geography University of Florida

Follow this and additional works at: https://scholarworks.umass.edu/ttra

Yang, Yang, "Domestic Tourism Demand of Urban and Rural Residents in China: Does Relative Income Matter?" (2016). Travel and Tourism Research Association: Advancing Tourism Research Globally. 29. https://scholarworks.umass.edu/ttra/2012/Visual/29

This Event is brought to you for free and open access by ScholarWorks@UMass Amherst. It has been accepted for inclusion in Travel and Tourism Research Association: Advancing Tourism Research Globally by an authorized administrator of ScholarWorks@UMass Amherst. For more information, please contact scholarworks@library.umass.edu. 


\title{
Domestic Tourism Demand of Urban and Rural Residents in China: Does Relative Income Matter?
}

Yang Yang

Department of Geography

University of Florida

\begin{abstract}
This research aims to investigate the domestic tourism demand of urban and rural residents in China. Multilevel models are applied to develop domestic tourism demand as a function of income, price of tourism, and substitute price. In the multilevel model, the relative income effect is explored by the interaction term between individual income and average income over city/province. Based on the estimation results, the paper substantiates the need to incorporate relative income to tourism demand study. Furthermore, regional differences between residents in different sub-regions and different patterns of determinants between urban and rural residents are identified and discussed.
\end{abstract}

Keywords: domestic tourism demand, China, multilevel model, relative income

\section{INTRODUCTION}

Along with the rapid growth of Chinese domestic tourism in the last decade, there is an increasing demand for tourism literature in this field for policy and marketing suggestions. However, few studies have focused on the determinants and mechanism of domestic tourism demand using econometric analysis (Cai, Hu, \& Feng, 2001; Cai \& Knutson, 1998; Z. Wang, 2010). The previous papers tried to explain the relationship between tourism demand and related factors, but their results, especially those regarding the sensitivity of income and price on domestic tourism, are less rigorous without scrupulous econometric modelling. This study is an important attempt to fill this gap in Chinese domestic tourism literature. By modelling domestic tourism demand of urban and rural residents, the study attempts to identify the determinants of Chinese domestic tourism demand and quantify their effects. Based on the results of this research, policy suggestions for tourism development and management at both country and regional levels can be offered.

This paper contributes to current literature in three major ways. First, as far as we are concerned, this paper represents one of the first attempts to introduce relative income to study tourism demand. By including this variable, we can capture the influence of social status/class on tourism demand. Since tourism demand research has been criticized for lacking concern for non-economic factors, our research is an important attempt to investigate this social variable in tourism demand analysis. Second, this paper applies multilevel models to analyze tourism demand, which allows for slope heterogeneity and interactions across different levels. Therefore, it is possible to quantify the heterogeneity of various determinants on domestic tourism, and to analyze the relative income effect through the interaction term. With the results from the models, this paper helps both government and private tourism sectors to understand domestic tourism demand of Chinese residents, and provides insights on 
resource allocation to satisfy residents' tourism demand along with income boom and pricing strategy to maximize profits. Third, since the urban-rural dichotomy induces different tourism demand for urban and rural residents, by comparing the results from models of urban and rural residents, practitioners can carry out more specific tourism planning and marketing strategies towards particular segments of domestic tourists.

\section{SOCIAL STATUS AND TOURISM DEMAND}

Apart from various economic factors, many other types of variables, including social variables, are believed to influence tourism demand. A typical social variable is the social status of tourists (Moeran, 1983; Mok \& Defranco, 2000; Song, et al., 2000). In order to better understand the relationship between social status and tourism demand, we borrowed two concepts from economics and sociology, namely, "conspicuous consumption" and "positional good".

Conspicuous consumption is a type of consumption that is designed to signal the social position and status of each individual (Veblen, 1967). With this in mind, tourism can communicate social status as it could be associated with higher personal income and more leisure time (Guo, Kim, \& Timothy, 2007; Todd, 2001). Furthermore, people often make their tourism consumption visible to others by pictures, souvenirs, and verbal descriptions. To symbolize social status during tourism, tourists sometimes purchase luxury products and services (Park, Reisinger, \& Noh, 2010) or consume fancy local foods (Kim, Eves, \& Scarles, 2009). Moeran (1983) highlighted the influences of social status on Japanese tourists' behaviour; depending on the social status, they might make different decisions on outbound travelling intentions, destination choice, travelling organization and duration of stay. However, the influence of social status on conspicuous tourism consumption might be more significant in China. As indicated by Mok and Defranco (2000), in Chinese culture, the symbolic value of goods and services are of great importance, and people regard status symbols as necessary in daily lives.

The theory of positional goods states that the utility of possessing positional goods is derived not only from the absolute amount but also the relative amount. It tends to reflect the social status through the consumption of a particular type of good in terms of the relative amount the individual possesses. Therefore, people with a higher relative income would consume a larger relative amount of positional goods to demonstrate their social status. Status-signalling goods are completely positional (Carlsson, Johansson-Stenman, \& Martinsson, 2007); and as argued by Urry (1990, 2003), the consumption of some modern tourism services can be regarded as positional goods.

Some empirical studies have analyzed the degree of positionality of vacations by using survey-experimental methods. Surveying faculty, students, and staff at the Harvard School of Public Health, Solnick and Hemenway (1998) found that vacation time is not positional, while based on a Swedish sample, Carlsson, et al.(2007) also 
argued that leisure is completely non-positional. However, Alpizar, Carlsson and Johansson-Stenman (2005) found the opposite from a sample of students at the University of Costa Rica and highlighted that relative consumption is important for vacations. Also, Solnick, Hong, and Hemenway (2007) found that vacation time is a positional good in China, while not in the U.S. Therefore, these results pinpoint the difference between developed and developing countries regarding the degree of positionality of vacations.

\section{DATA DESCRIPTION AND MODEL SPECIFICATION}

As mentioned before, we are going to use multilevel models to analyze domestic tourism demand in China, covering a sample of urban residents in thirty five major cities from 1996 to 2007 and rural residents in thirty provinces from 2000 to 2007. By doing so, we are able to identify two sources of random variation in our domestic tourism demand model: within- and between- city/province variation. Panel data models, frequently used econometric models for tourism demand analysis (Song \& Li, 2008), can be regarded as special cases of multilevel models by specifying yearly observations nested in panels (i.e. countries of origin). To construct the multilevel model of domestic tourism demand, we conceptualize two levels: resident individuals (at level-1) nested within the cities/provinces in which they live (at level-2). To accommodate this multilevel structure, we specify two levels in the model as:

$$
\begin{gathered}
\ln D_{i j t}=\beta_{i}+\beta_{1} \ln P_{i j t}+\beta_{2} \ln P S_{i j t}+\beta_{3} S A R S_{t}+\beta_{4} G W_{t}+\sum_{k=2}^{7} \gamma_{i t}^{(k)} i n c(k)_{i j t}+\varepsilon_{i j} \\
\beta_{i}=\beta_{0}+\alpha_{i} \\
\gamma_{i t}^{(k)}=\gamma_{0}^{(k)}+\delta^{(k)} \ln \text { aver_inc }_{i t}+\xi_{i}^{(k)}, \quad \text { for } k=2 \text { to } 7
\end{gathered}
$$

where Equation 1 represents the level-1equation while Equations 2 and 3 represent the level-2 equations, explaining the constant and slope heterogeneity across level-2 units, respectively. $i$ represents the level-2 unit, which is the city for urban residents and the province for rural residents, $j$ represents resident individual, and $t$ represents the year of observation. $D$ is the annual domestic tourism expenditure per person. $P$ is the tourism price index, $P S$ is the substitute price index to tourism, SARS is a dummy variable indicating the outbreak of SARS at the year of 2003 (SARS $=1$ if $t=2003$, and 0 , otherwise), and $G W$ is a dummy variable to capture the impact of the Golden Week policy from 1999 ( $G W=1$ if $t>1999$, and 0 , otherwise). Since we could only get the interval data of tourists' income instead of continuous data, a set of dummy variables, inc(2) to inc(7), are used to capture income effects, leaving inc(1) as the reference. The definition of these income dummies for urban and rural residents can be found in Table 1. For the level-2 equations, Equation 2 incorporates random effect $\alpha_{i}$ of each city/province on the constant, which is used to capture unobserved city/province specific factors influencing tourism demand which has not been included in our model, such as location relative to major tourist attractions and 
traveling cultures. In Equation 3, aver_inc denotes the average disposable income over the city/province, and a set of $\xi_{i}^{(k)}(k=2$ to 7$)$ represent another six random effects. In the specified model, all random effects, $\varepsilon_{i j t}, \alpha_{i}$ and $\xi_{i}^{(k)}$ (k=2 to 7), are assumed to be independent from each other and follow normal distributions with a zero mean and a finite variance. We take the log of all continuous variables, and therefore, their estimated coefficient can be interpreted as the elasticity, accordingly. We are constructing the tourism price index following the origin-destination matrix weighted method by Lanza, Temple and Urga (2003). In terms of substitute price, instead of using outbound tourism price index (Allen, Yap, \& Shareef, 2009; Hamal, 1996), we are going to use the local price index of cultural activities and entertainment by assuming that local cultural activities and entertainment is a substitute good to domestic tourism.

Our domestic tourism demand data is derived from the National Household Tourism Survey, and we obtained the dataset from the China Domestic Tourist Survey Yearbook (1997-2007). The price data comes from the Price Yearbook of China. This dataset is partially aggregated compared to the traditional aggregate data used in past tourism demand analyses (Y. Wang \& Davidson, 2010). In previous tourism demand research, the demand data is aggregated based on administrative units or statistical units. Hence, it imposes the restriction of full homogeneity on data by assuming that each individual within the unit is uniform in terms of economic and social-demographic status. For the partially aggregate data, data is aggregated by different income groups nested in each administrative unit. Even though the homogeneity problem is still difficult to overcome, our approach is better because at least personal income information can be identified. To disaggregate this data, we weight the data in the model by the number of observations in each income group within the sample unit.

The multilevel model accounts for the heterogeneity across different levels by specifying the random effects over particular levels, such as $\alpha_{i}$ and $\xi_{i}^{(k)}$ specified in Equations 2 and 3. Furthermore, in the specified model, social status/class is measured by personal income relative to average income in the city/province where they live. By substituting Equation 3 into Equation 1 we obtain the interaction terms between individual income and average income in the city/province. A negative estimated coefficient of these interaction terms can be used to identify the relative income effect. For example, conditional on the same personal income of two people, the one living in the region with a lower average income suggests a higher social status/position. This relative income effect indicates that he or she has a higher domestic tourism demand than the other one given the same price and substitute price they are facing. If these interactions are estimated to be positive, it would indicate a demonstration effect in domestic tourism demand, and this demand will be influenced by other people in the region where they live (Duesenberry, 1949; Galbraith, 1958). 
As other people become wealthier and, therefore, allocate more of their budgets to domestic tourism consumption, residents will imitate and follow others by purchasing more domestic tourism as well.

The descriptive statistics for the variables included in the empirical model are presented in Table 1. The sample covers 138,797 urban residents and 40,840 rural residents. Although $\ln P$ and $\ln P S$ are level-1 variables, we could only observe price variables for a city at a period instead of that for each individual resident. Therefore, it is assumed that residents in the same city/province at the same year are facing the same price and substitute price for domestic tourism, and there are 420 observations of $\ln P$ and $\ln P S$ for urban residents and 240 observations for rural residents, which is the same number as the observation of level-2 variable lnaver inc. Among urban residents, 54.04\% falls into income groups 3 and 4, with a monthly income between 1,000 and 2,999 RMB Yuan during the study period; while among rural residents, the sample is relatively evenly distributed across different income groups.

Table 1

Descriptive Statistics of Variables

Urban Resident Model

$\begin{array}{rcccccc}\text { Continuous } & \text { Mean } & \begin{array}{c}\text { Standard } \\ \text { Deviation }\end{array} & \begin{array}{c}\text { Number of } \\ \text { Observations }\end{array} & \text { Mean } & \begin{array}{c}\text { Standard } \\ \text { Deviation }\end{array} & \begin{array}{c}\text { Number of } \\ \text { Observations }\end{array} \\ \ln D & 6.463 & 0.591 & 138797 & 6.306 & 0.559 & 40840 \\ \ln P & 4.626 & 0.039 & 420 & 4.589 & 0.078 & 240 \\ \ln P S & 4.632 & 0.088 & 420 & 4.627 & 0.057 & 240 \\ \text { lnaver_inc } & 9.077 & 0.418 & 420 & 7.980 & 0.425 & 240 \\ \text { Categorical } & \text { Monthly Income } & \text { Frequency } & \text { Percent } & \text { Annual Income } & \text { Frequency } & \text { Percent } \\ \text { Variable } & \text { (in RMB Yuan) } & & & \text { (in RMB Yuan) } & & 10.44 \\ \text { inc(1) } & \sim 499 & 4339 & 3.12 & \sim 1499 & 4265 & 14.38 \\ \text { inc(2) } & 500 \sim 999 & 15861 & 11.42 & 1500 \sim 1999 & 5874 & 16.53 \\ \text { inc(3) } & 1000 \sim 1999 & 43636 & 31.42 & 2000 \sim 2499 & 6750 & 13.57 \\ \text { inc(4) } & 2000 \sim 2999 & 31415 & 22.62 & 2500 \sim 2999 & 5541 & 19.74 \\ \text { inc(5) } & 3000 \sim 3999 & 19212 & 13.83 & 3000 \sim 3999 & 8061 & 10.87 \\ \text { inc(6) } & 4000 \sim 4999 & 10735 & 7.73 & 4000 \sim 4999 & 4439 & 14.48 \\ \text { inc(7) } & 5000 \sim & 13676 & 9.85 & 5000 \sim & 5915 & \end{array}$

Rural Resident Model

Standard Number of

vations

240

6.53

\section{RESULTS}

\section{Demand model for urban residents}

Table 2 presents the estimation results of domestic tourism demand models for urban residents. The first three models in the table, Urban-All1, Urban-All2, and Urban-All3 models, include all 138,797 observations across thirty five cities. In Urban-All1 model, the baseline model, we assume that the income effect is constant 
across all cities, and do not consider the relative income effect; while in Urban-All2 model, we include the additional heterogeneity of income effects by including the random effects in the slope coefficient of the income effects as $\xi_{i}^{(k)}$ in Equation 3.

The estimation results are very similar between Urban-All1 and Urban-All2 models. The estimated coefficients of inc(2) to inc(7) are positive, statistically significant, and in an ascending order, suggesting a positive and significant absolute income effect on domestic tourism demand of China's urban residents. $\ln P$ is estimated to be negative and significant, while $\ln P S$ is positive and significant, which are consistent with economic theories. The estimated price elasticity is larger than 1, indicating that domestic tourism is elastic to Chinese urban residents. Furthermore, as indicated by the negative and significant coefficient of SARS, the SARS outbreak in 2003 contributes to a $12.6 \%$ decline of domestic tourism demand of urban residents. However, the estimated coefficient of $G W$ is not significant, suggesting that the Golden Week policy has limited impact on Chinese domestic tourism demand, which confirms the findings from Wang (2010). This may be explained by the fact that, although the Golden Week policy stimulated the tourism demand in certain periods of the year, the overall domestic tourism demand of the whole year is unaffected. Tourists may change their traveling schedule to accommodate this policy change. They spend more during Golden Weeks, while cut down tourism consumption at the rest time of the year, making the overall yearly demand unaffected.

Table 2

Estimation Results for Domestic Tourism Demand of Urban Residents

\begin{tabular}{|c|c|c|c|c|c|c|c|c|}
\hline Variable & Urban-All1 & Urban-All2 & Urban-All3 & Urban-P1 & Urban-P2 & Urban-East & Urban-Center & Urban-Wes \\
\hline \multirow[t]{2}{*}{$\operatorname{inc}(2)$} & $0.404 * * *$ & $0.405 * * *$ & $3.214^{* *}$ & -2.580 & $6.971 * *$ & $4.323 *$ & -1.035 & 4.308 \\
\hline & $(0.0648)$ & $(0.0654)$ & $(1.628)$ & $(2.262)$ & $(2.831)$ & $(2.450)$ & $(1.883)$ & $(3.062)$ \\
\hline $\operatorname{inc}(3)$ & $(0.0733)$ & $(0.0624)$ & $(1.459)$ & $(1.746)$ & $(1.607)$ & $(1.507)$ & $(1.759)$ & $(2.896)$ \\
\hline $\operatorname{inc}(4)$ & $0.869 * * *$ & $0.901 * * *$ & $3.761 * * *$ & 3.225 & $3.390 * *$ & $4.882 * * *$ & -1.253 & $7.292 * * *$ \\
\hline \multirow[t]{2}{*}{$\operatorname{inc}(5)$} & $1.010 * * *$ & $1.028 * * *$ & $4.522 * * *$ & 3.184 & $5.566 * * *$ & $6.620 * * *$ & 0.440 & 4.010 \\
\hline & $(0.0735)$ & $(0.0687)$ & $(1.493)$ & $(3.359)$ & $(1.632)$ & $(1.457)$ & $(3.129)$ & $(3.536)$ \\
\hline \multirow[t]{2}{*}{$\operatorname{inc}(6)$} & $1.086 * * *$ & $1.142 * * *$ & 2.410 & -1.174 & $3.271 *$ & $5.746 * * *$ & -5.610 & -3.389 \\
\hline & $(0.0866)$ & $(0.0822)$ & (1.785) & $(4.582)$ & (1.824) & (1.634) & $(5.508)$ & $(3.596)$ \\
\hline $\ln P$ & $(0.703)$ & $(0.701)$ & $(0.902)$ & $(1.055)$ & $(0.938)$ & $(0.671)$ & $(1.985)$ & $(1.651)$ \\
\hline \multirow[t]{2}{*}{$\ln P S$} & $0.930 * * *$ & $0.940 * * *$ & $1.123 * * *$ & 0.0542 & -0.0329 & $1.501 * * *$ & 0.325 & 0.785 \\
\hline & $(0.309)$ & $(0.313)$ & $(0.357)$ & $(0.300)$ & $(0.586)$ & $(0.380)$ & $(0.549)$ & $(0.808)$ \\
\hline \multirow[t]{2}{*}{$S A R S$} & $-0.126^{* * *}$ & $-0.126^{* * *}$ & $-0.114 * * *$ & & $-0.0912 * *$ & $-0.168 * * *$ & -0.0463 & -0.0453 \\
\hline & $(0.0379)$ & $(0.0388)$ & $(0.0409)$ & & $(0.0448)$ & $(0.0461)$ & $(0.0446)$ & $(0.0878)$ \\
\hline$G W$ & -0.0426 & -0.0513 & -0.000827 & 0.0153 & & 0.00155 & 0.0539 & -0.0417 \\
\hline
\end{tabular}




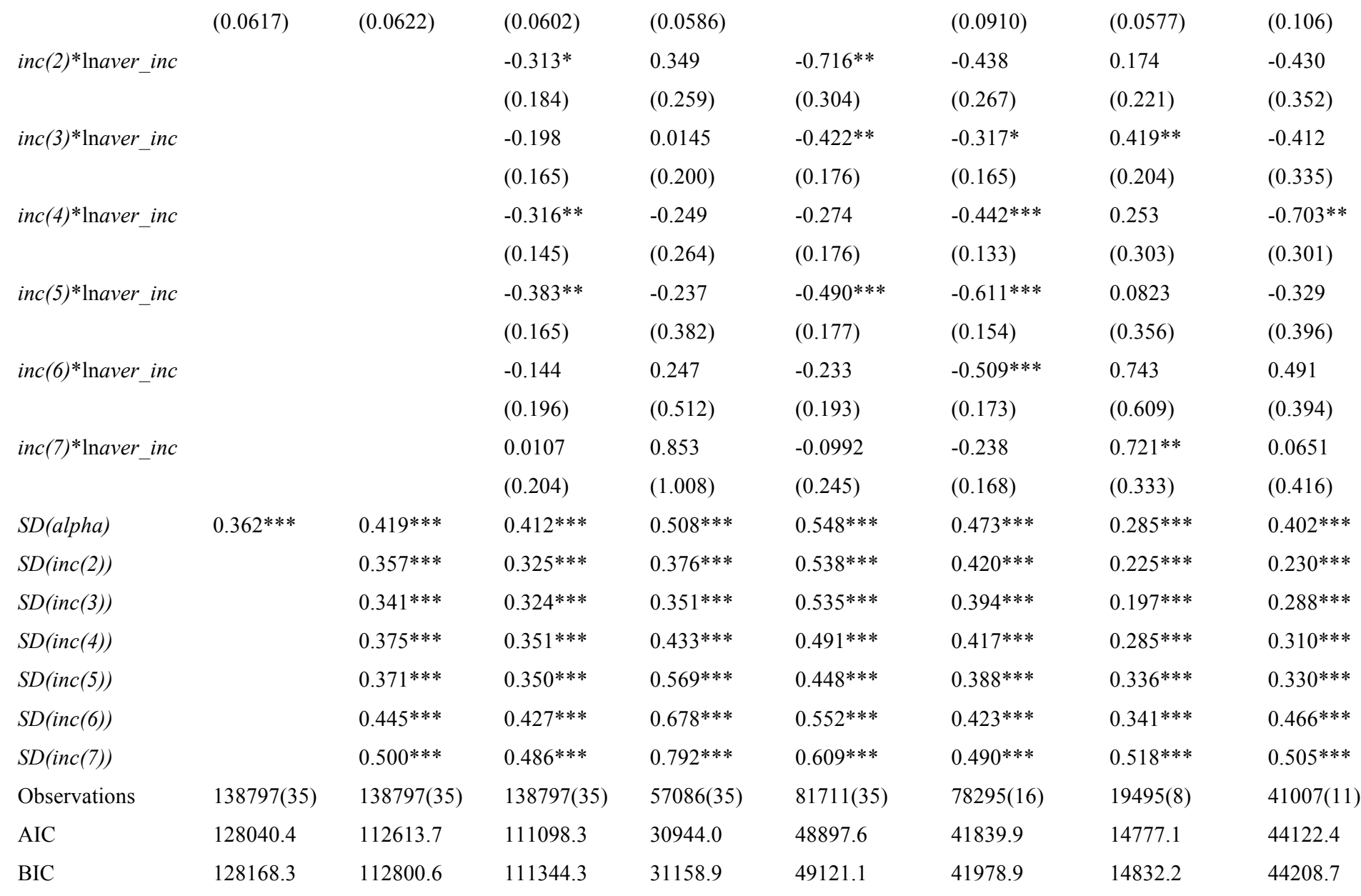

(Notes: * indicates $p<0.10, * *$ indicates $p<0.05, * * *$ indicates $p<0.01$.Robust standard error in parenthesis. The estimates of level1-1 constants and random effect of level-1 error are not presented. SD(.) indicates the estimated standard deviation of random effects)

As suggested by the estimates of $S D($.$) in Table 2, all random effects in$ Equations 2 and 3 are estimated to be statistically significant, highlighting the heterogeneity across cities. From the estimated standard deviation of each random effect, we can compare the degree of this heterogeneity. For example, the estimated standard deviation of random effect of high-income residents, like $S D($ inc(6)) and $S D$ (inc(7)) are larger, suggesting a more intense cross-city heterogeneity in income effects for high-income residents.

Urban-All3 model is a further extension to the previous two models by considering the interaction of individual income and city-average income, which is used to capture the effect of relative income. After introducing these interaction terms, the estimated coefficient of $\ln P$ becomes statistically insignificant albeit still negative. However, $\ln P S$ is estimated to be positive and significant. The interpretation of income effects becomes complicated in this model. For a set of absolute income dummy variables, we found that inc(6) and inc(7) are not statistically significant. For interaction terms, the interaction terms inc(2)*lnaver_inc, inc(4)*Inaver_inc and inc (5)*Inaver_inc are statically significant and negative, highlighting the significant 
relative income effect for middle- and low-income residents. The negative estimated coefficient suggests that, conditional on the absolute personal income, a higher relative income is associated with a higher domestic tourism demand for urban residents in China. This highlights the importance of social status in determining domestic tourism demand. To symbolize and communicate one's prestige and social position, they are more likely to spend more on domestic tourism.

We split our sample to further investigate the change of domestic tourism demand over time. Urban-P1 model in Table 2 covers the period from 1996 to 2001, while Urban-P2 model includes observations from 2002 to 2007. By comparing the estimates from these two models, an important finding is that the interaction terms are only estimated to be statistically significant and negative over the period from 2002 to 2007, emphasizing the fact that the relative income did not play an important role in determining domestic tourism demand of urban residents until recently. One possible explanation would be the change of domestic tourism patterns over time. In the past, domestic tourism was characterized by sightseeing activities with economic services, while after 2000, more and more domestic tourists choose to take vacation, purchase some luxury goods and services, and maintain high comforts during travel. As a result, domestic tourism becomes more status-symbolizing, and the relationship between relative income and domestic tourism demand turns to be significant.

In the last three columns of Table 2, we estimate the model including relative income effects with the sample in different geographic sub-regions. From Urban-East, Urban-Center and Urban-West models, we found that, with regard to price variables, only $\ln P S$ is statistically significant for the East, and it is estimated to be positive. In terms of SARS outbreak, the negative and significant coefficient of SARS in Urban-East model suggests that the SARS outbreak only exerts significant negative impacts on domestic tourism demand of urban residents in the East. This can be explained by the higher incidence of SARS in the East according to China Statistical Yearbook of Health, and it is consistent with the finding from Yang and Wong (forthcoming). In all of three models, $G W$ is estimated to be insignificant. We found different relative income effects across different regions. The relative income effect on domestic tourism demand is most significant in the East as four out of six interaction terms are estimated to be significant and negative, indicating a significant relationship between relative income and domestic tourism demand for urban resident in the East with a monthly income from 1,000 to 4,999 RMB Yuan. For urban residents in the West, the relative income effect is found to be significant for residents with monthly incomes from 2,000 to 2,999 RMB Yuan. It is surprising to note that two interaction terms representing relative income effects are estimated to be significant and positive in Urban-Center model, suggesting the demonstration effect in domestic tourism demand is significant in some income groups of central urban residents.

\section{Demand model for rural residents}


We are going to use the same methods to look into the domestic tourism demand of rural residents. Table 3 presents the estimation results from models for Chinese rural residents across thirty provinces over the period of 2000-2007. Since this period does not cover the policy change of Golden Weeks, the variable $G W$ is excluded in all models. Rural-All1 and Rural-All2 models are the baseline model and the model with province heterogeneity over income effects, respectively. Variables inc(2) to inc(7) are estimated to be positive, significant and in an ascending order, emphasizing the positive impact of absolute income on domestic tourism demand of Chinese rural residents. $\ln P$ is not statistically significant albeit negative, while $\ln P S$ is statistically significant and positive. The estimated substitute elasticity by Rural-All2 model is 1.622, and it is larger than the one from Urban-All2 model, which is merely 0.940 . This suggests the substitution effect of local cultural activities and entertainment to domestic tourism is stronger for rural residents. Another major difference by comparing Rural-All2 and Urban-All2 models is the impact of SARS outbreak on domestic tourism demand. While it is significant and negative for urban residents, it is not significant for rural residents.

Table 3

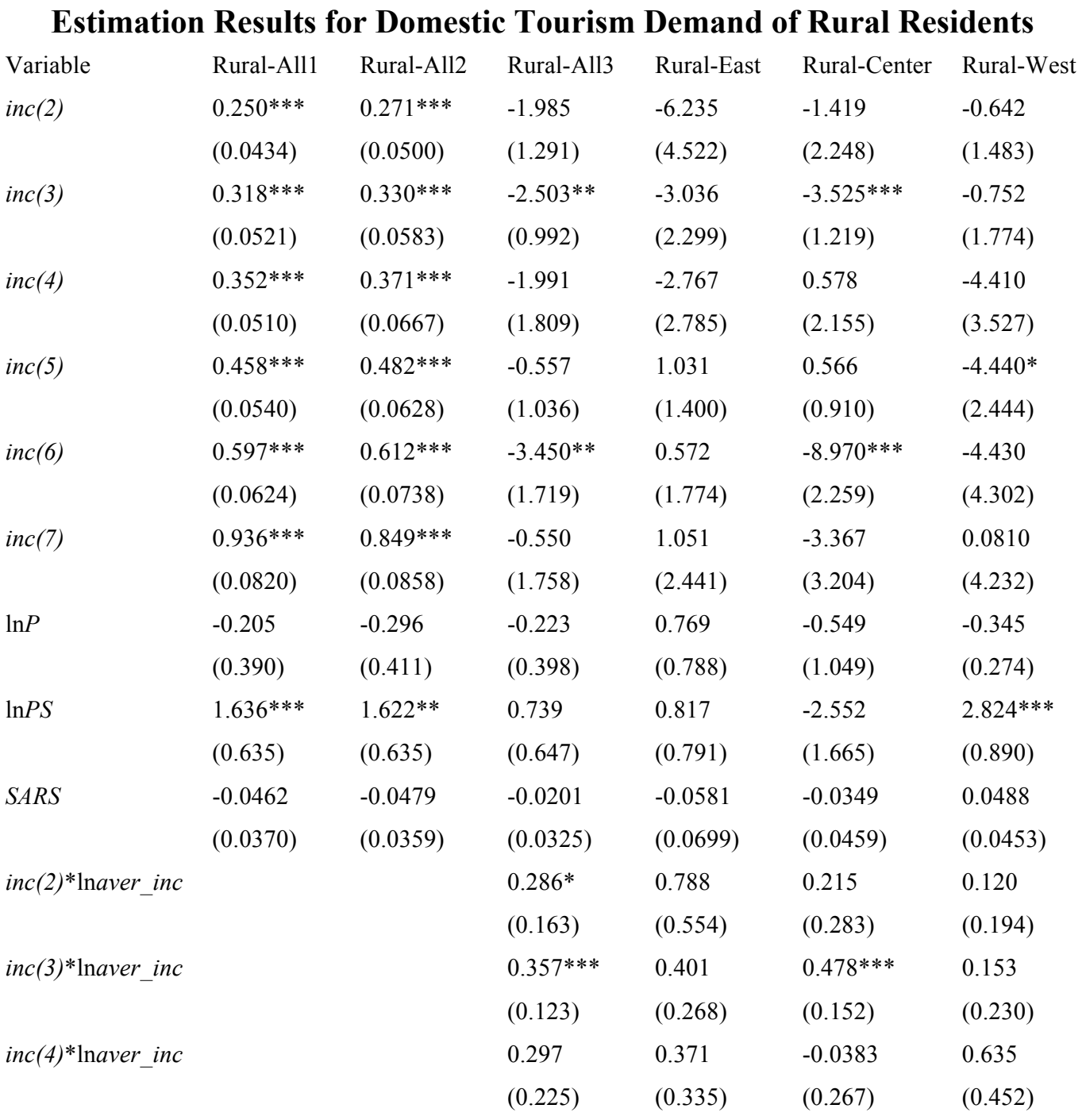




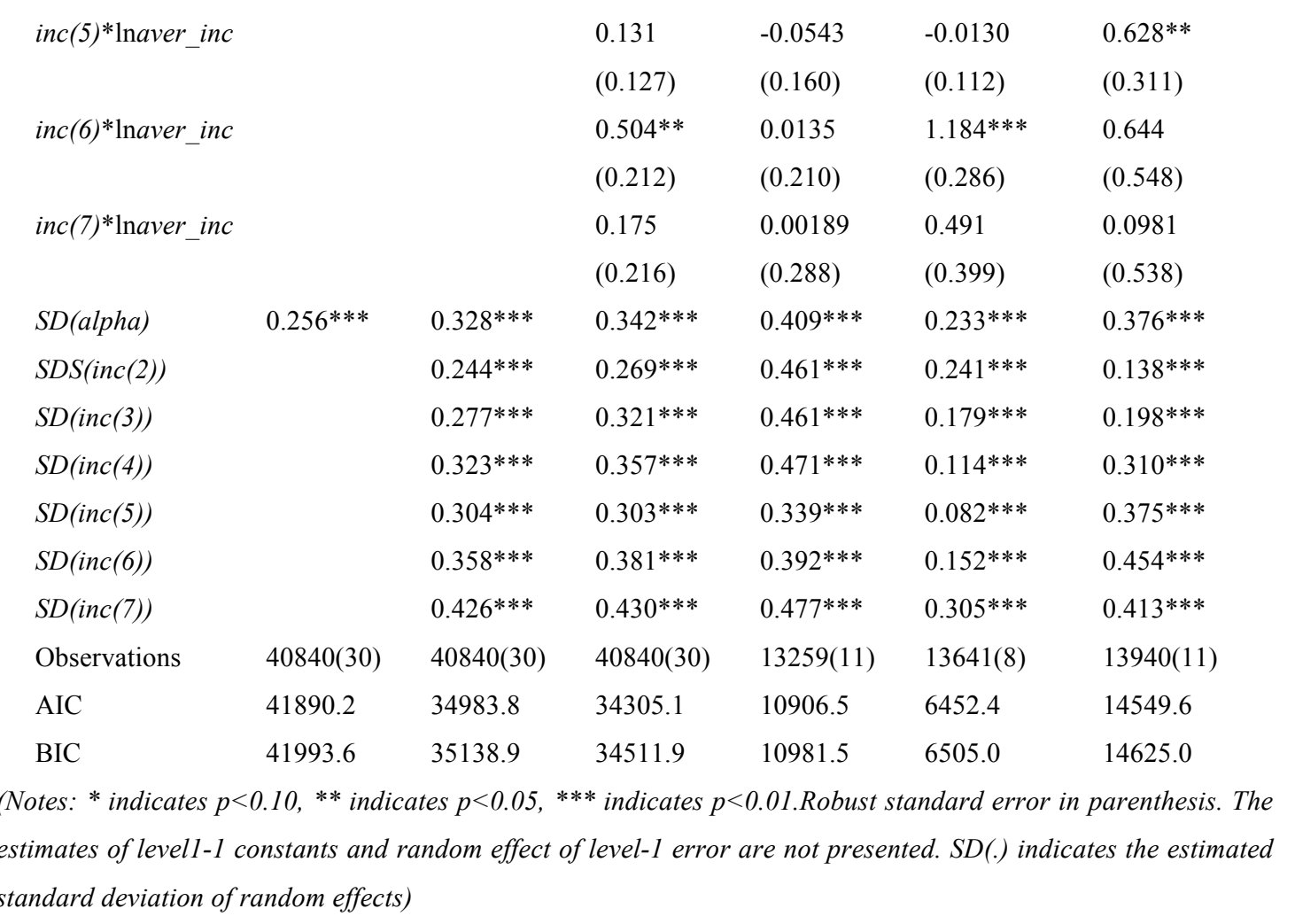

Regarding the slope heterogeneity in Urban-All2 model, we found that all random effects are estimated to be statistically significant. This indicates that the income effects on rural residents' domestic tourism demand are also heterogeneous across different provinces. In Rural-All3 model, we include the interaction term of absolute income and province-average income to investigate the effect of relative income on rural residents' domestic tourism demand. Two of six interaction terms are estimated to be statistically significant and positive. This suggests that the demonstration effects might be significant among some rural residents. The result is different from that in the urban residents' model, which highlight that higher relative income is associated with higher domestic tourism demand. One possible explanation is that compared to urban residents, rural residents travel in a more economic and utilitarian way, and therefore less status-signaling (N. Wang, 2004), making tourism a less conspicuous consumption.

\section{CONCLUSION}

This research applies multilevel models to investigate the domestic tourism demand of urban and rural residents in China. The partially aggregate data from the National Household Tourism Survey covers urban residents in thirty five major cities from 1996 to 2007 and rural residents in thirty provinces from 2000 to 2007. This paper breaks new ground by estimating the effect of relative income in determining domestic tourism demand, and highlights the significant relative income effect on some urban residents' tourism demand. Moreover, own price is estimated to be significant only for urban residents, while substitute price is significant for both urban and rural residents. With regard to the impact of SARS outbreak, we found that it 
exerted significant and negative impacts on urban residents' domestic tourism demand while not on rural residents'. For both urban and rural residents, there is no statistical evidence to support the stimulation effect of the Golden Week policy on domestic tourism demand.

Based on the findings from this research, several implications in terms of government policy and marketing strategy can be provided. First, when making marketing plans to target potential tourists, relative income should be another important factor to consider apart from absolute income, as it determines the level of domestic tourism demand. Second, different marketing strategies should be proposed for residents in different areas and resident in urban and rural areas. For example, urban residents in the East are more social status concerning, while Western urban residents are more absolute income sensitive. Third, conditional on the fixed price, tourism products and services should be designed to be more status-signaling to satisfy the needs of urban residents, especially for urban residents in Eastern cities.

\section{REFERENCES}

Allen, D., Yap, G., \& Shareef, R. (2009). Modelling interstate tourism demand in Australia: A cointegration approach. Mathematics and Computers in Simulation, 79(9), 2733-2740.

Alpizar, F., Carlsson, F., \& Johansson-Stenman, O. (2005). How much do we care about absolute versus relative income and consumption? Journal of Economic Behavior \& Organization, 56(3), 405-421.

Cai, L. A., Hu, B., \& Feng, R. (2001). Domestic tourism demand in China's urban centres: Empirical analyses and marketing implications. Journal of Vacation Marketing, 8(1), 64-74.

Cai, L. A., \& Knutson, B. J. (1998). Analyzing domestic tourism demand in China - A behavioral model. Journal of Hospitality \& Leisure Marketing, 5(2-3), 95-113.

Carlsson, F., Johansson-Stenman, O., \& Martinsson, P. (2007). Do you enjoy having more than others? Survey evidence of positional goods. Economica, 74(296), 586-598.

Clark, A. E., Frijters, P., \& Shields, M. A. (2008). Relative income, happiness, and utility: An explanation for the Easterlin Paradox and other puzzles. Journal of Economic Literature, 46(1), 95-144.

Duesenberry, J. S. (1949). Income, Savings, and the Theory of Consumer Behaviour. Cambridge: Harvard University Press.

Galbraith, J. K. (1958). The Affluent Society. Boston, MA: Houghton Mifflin.

Guo, Y., Kim, S. S., \& Timothy, D. J. (2007). Development characteristics and implications of mainland Chinese outbound tourism. Asia Pacific Journal of Tourism Research, 12(4), 313-332.

Hamal, K. (1996). Modeling domestic holiday tourism demand in Australia: Problems and solutions. Asia Pacific Journal of Tourism Research, 1(2), 35-46.

Kim, Y. G., Eves, A., \& Scarles, C. (2009). Building a model of local food consumption on trips and holidays: A grounded theory approach. International 
Journal of Hospitality Management, 28(3), 423-431.

Lanza, A., Temple, P., \& Urga, G. (2003). The implications of tourism specialisation in the long run: An econometric analysis for 13 OECD economies. Tourism Management, 24(3), 315-321.

Lim, C. (1997). Review of international tourism demand models. Annals of Tourism Research, 24(4), 835-849.

Moeran, B. (1983). The language of Japanese tourism. Annals of Tourism Research, 10(1), 93-108.

Mok, C., \& Defranco, A. L. (2000). Chinese cultural values: Their implications for travel and tourism marketing. Journal of Travel \& Tourism Marketing, 8(2), 99-114.

Park, K.-S., Reisinger, Y., \& Noh, E.-H. (2010). Luxury shopping in tourism. International Journal of Tourism Research, 12(2), 164-178.

Sauran, A. (1978). Economic determinants of tourist demand: A survey. Tourism Review, 3(1), 2-4.

Solnick, S. J., \& Hemenway, D. (1998). Is more always better?: A survey on positional concerns. Journal of Economic Behavior \& Organization, 37(3), 373-383.

Solnick, S. J., Hong, L., \& Hemenway, D. (2007). Positional goods in the United States and China. Journal of Socio-Economics, 36(4), 537-545.

Song, H., \& Li, G. (2008). Tourism demand modelling and forecasting-A review of recent research. Tourism Management, 29(2), 203-220.

Song, H., Peter, R., \& Liu, X. (2000). An empirical study of outbound tourism demand in the UK. Applied Economics, 32(5), 611-624.

Todd, S. (2001). Self-concept: A tourism application. Journal of Consumer Behaviour, 1(2), 184-196.

Urry, J. (1990). The 'consumption' of tourism. Sociology, 24(1), 23-35.

Urry, J. (2003). The 'Consumption' of Tourism. In D. B. Clarke, M. A. Doel \& K. M. L. Housiaux (Eds.), The Consumption Reader (pp. 117-121). London: Routledge.

Veblen, T. (1967). The Theory of the Leisure Class. New York: Penguin Books.

Wang, N. (2004). The rise of touristic consumerism in urban China. Tourism Recreation Research, 29(2), 47-58.

Wang, Y., \& Davidson, M. C. G. (2010). A review of micro-analyses of tourist expenditure. Current Issues in Tourism, 13(6), 507-524.

Wang, Z. (2010). Factors that Influence the gowth of Chinese domestic tourism arrivals (1985-2007) - An empirical research based on the VAR model. Asia Pacific Journal of Tourism Research, 15(4), 449-459.

Yang, Y., \& Wong, K. K. F. (forthcoming). A spatial econometric approach to model spillover effects in tourism flows. Journal of Travel Research. 